\title{
Easing Employee Strain: The Interactive Effects of Empowerment and Justice on the Role Overload-Strain Relationship
}

\author{
Martha C. Andrews \\ University of North Carolina \\ Wilmington, NC. \\ K. Michele Kacmar \\ University of Alabama \\ Tuscaloosa, AL.
}

\begin{abstract}
Author's Notes
Correspondence concerning the article should be addressed to Martha Andrews, Department of Management, University of North Carolina, Wilmington, NC, 28403-5969. E-mail: Contact: andrewsm@uncw.edu
\end{abstract}

\begin{abstract}
The present study provides two tests of Karasek's (1979) Job Demand-Control Model using a sample of 159 employees from a pharmaceutical manufacturing facility. Empowerment and informational justice were conceived of as high control and low control, respectively and were examined for their moderating effects on two relationships: 1) the relationship between role overload and burnout and 2) the relationship between role overload and job satisfaction. All four hypotheses were supported. Findings indicate empowerment weakens the positive role overloadburnout relationship and the negative role overload-job satisfaction relationship. Informational justice strengthens the positive role overload-burnout and negative role overload-job satisfaction relationships.
\end{abstract}

Keywords: empowerment, informational justice, burnout, job satisfaction, role overload

\section{Introduction}

An increase in downsizing due to the economy has left many surviving workers feeling overwhelmed as they are asked to fill in the gaps left by laid off workers. They often experience increased expectations and responsibilities along with longer working hours. When work is increased so much that it becomes unmanageable, workers can experience role overload (Rizzo, House, \& Lirtzman, 1970). This form of work stress can lead to reduced job satisfaction and commitment and increased burnout, turnover (Jones, Chonko, Rangarajan, \& James, 2007), and numerous negative health outcomes (Shultz, Wang, \& Olson, 2010). However, not all individuals respond in the same way to increased work demands. While several approaches have been offered to explain these differences, of particular interest to the current study is Karasek's (1979) Job Demand-Control model.

Karasek's (1979) Job Demand-Control model contends individuals with high demands but low decision latitude (i.e., control) will experience the highest level of strain (i.e., high strain 
jobs) whereas individuals with low work demands but high decision latitude will experience little strain (i.e., low strain jobs). High work demands accompanied by low decision latitude also lead to job dissatisfaction (Karasek, 1979). The notion that certain variables can lessen the effects of role strain on negative outcomes has been referred to in the literature as the buffer hypothesis (van der Doef \& Maes, 1999).

In organizations, empowerment can be construed as high decision latitude as it provides individuals resources to cope with excessive work demands. Empowerment generally means providing employees with the autonomy to make decisions that affect how and in what ways they may complete their work (Ford, Fottler, Russ, \& Millam, 1995). Workers with low decision latitude have little control over the work situation. Limited control over one's schedule and how to carry out work tasks are also characteristic of low control situations (Parker \& Sprigg, 1999). Additional examples of low control include having to follow a set ordering of tasks, no influence over the amount of work that gets done as well as no influence over the policies and procedures in the workplace (Dwyer \& Ganster, 1991). Workers who must follow specific policies and procedures in completing their work likely have little decision latitude. Supervisors of workers in low control situations may provide explanations for why formal procedures must be followed. These explanations can create buy-in from the employees. However, as employees buy-in they also sacrifice a desire or need for control over the process of completing their work. In the present study, the extent to which supervisors provide explanations for policies and procedures (i.e., informational justice), is considered a low control situation. Finally, role overload, or excessive work demands given the time allowed, is considered high demands (Karasek, 1979).

\section{Theoretical Background and Hypothesis Development}

The present study is a test of Karasek's Job Demands-Control model that explores both buffering and strengthening effects of two measures of control on two role-overload-strain relationships. The relationships tested are shown in Figure 1. Specifically, we first examine a high control situation as we test the buffering effects of empowerment on the positive roleoverload-burnout relationship and the negative role-overload-satisfaction relationship. We also examine a low control situation as we test the strengthening effects of informational justice on the role-overload-burnout and role-overload-satisfaction relationships. This study provides a contribution to the stress literature as it includes a test of both high control (i.e., empowerment) and low control (i.e., informational justice) as moderators of these relationships. Additionally, this study responds to calls for tests of matching the level of demands with the level of controls in order to more adequately examine the interactive effects of control (Häusser, Mojzisch, Niesel, \& Schulz-Hardt, 2010). The matching hypothesis suggested buffering effects (i.e., moderator effects) would most likely occur if the support provided was most relevant to the demands required (Cohen \& Wills, 1985). 


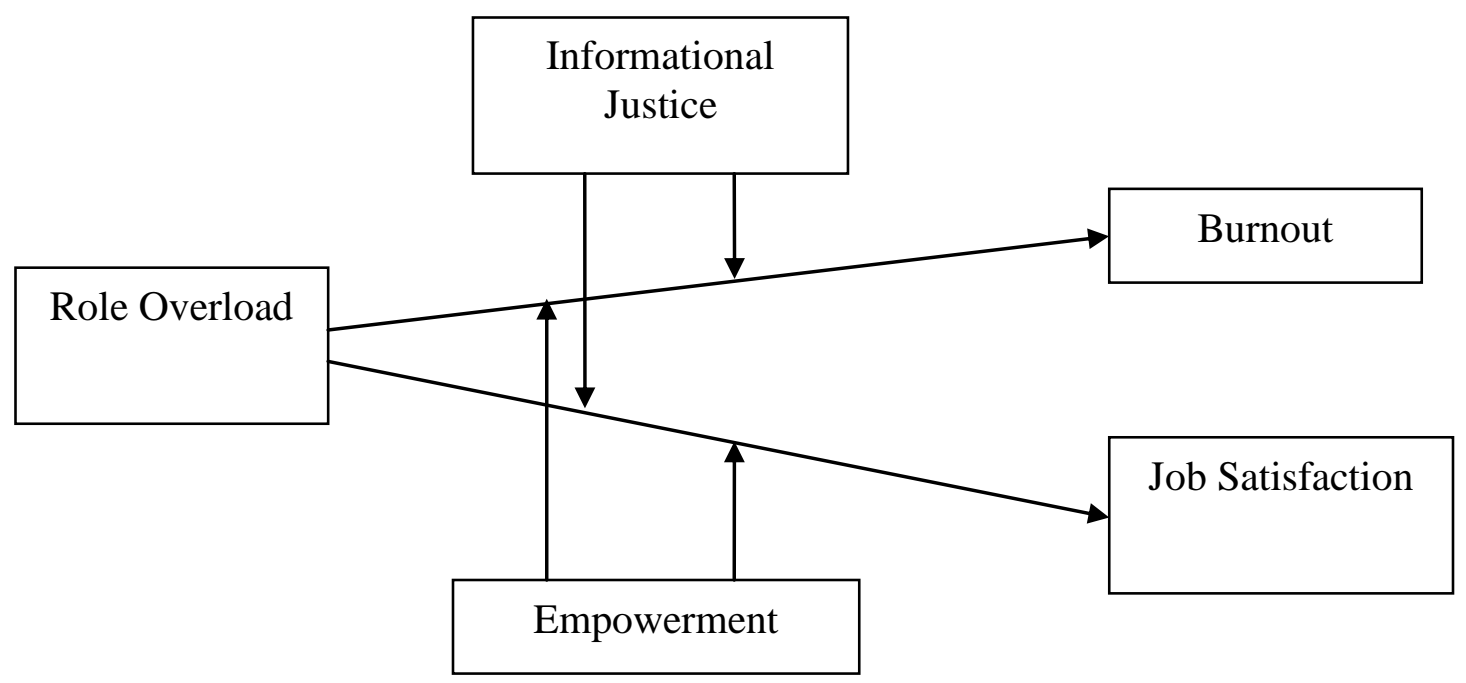

Figure 1. Hypothesized model.

\section{Job Demand Control Model}

Karasek's (1979) Job-Demand Control model focuses on the decision latitude (i.e., control) and demand aspects of the work environment at the individual level and how they influence job satisfaction and mental strain. He clarified these terms as follows: Stressors are job demands such as excessive workload and insufficient time to complete tasks. Job control is the extent to which individuals can participate in decisions and have a say about how work is completed. Job strain is the combination of high work demands and low decision latitude. Karasek suggested that it is not job demands alone that impact mental strain and job satisfaction but rather the combination of job demands and decision latitude. His research indicated that when workers have discretion in determining how they can meet excessive job demands, they experience less strain and job dissatisfaction.

Empirical support for the JD-C model has been inconsistent (Hausser et al., 2010). Hauser et al. found support for the interactive effects in thirty percent of the studies included in their meta-analysis. Thus, they offered the matching principle as a way of improving the buffering effect of control as a potential moderator. They suggested testing models in which the degree of demand and control given to employees match. For example, control over schedule or ordering of work would be less effective buffering emotional demands than it would be buffering demands resulting from increased workload.

\section{Effects of Role Overload on Burnout and Job Satisfaction}

Karasek (1979) described job demands in terms of quantitative facets of work load and time. Role overload is a role stressor that occurs when the perceptions of one's work demands exceeds his or her ability to successfully complete the assigned work (van der Doef \& Maes, 1999). Thus, consistent with other researchers, we examine role overload as an indicator of job 
demands (e.g., Wincent \& Ortqvist, 2011). A recent meta-analysis of Karasek's (1979) Job Demand-Control Model indicated two measures of job strain - burnout and job satisfaction - as the two primarily examined outcomes of excessive demands (Häusser et al., 2010). Burnout occurs in response to continually increasing job demands and consists of burnout, depersonalization, and reduced feelings of personal accomplishment (Cordes \& Dougherty, 1993). Job satisfaction refers to overall feelings of satisfaction regarding one's job (Caplan, Cobb, French, Harrison, \& Pinneau, 1975). Research has consistently shown role overload is positively related to burnout and negatively related to job satisfaction (e.g., Chou \& Robert, 2008; Hauser et al., 2010; Kissner, 1999; Malik, Waheed, \& Malik, 2010; Yip, Rowlinson, \& Oi Ling, 2008).

\section{Empowerment as High Control}

In the organizational context, empowerment has been conceptualized in two ways: psychological and structural. Psychological empowerment (Conger \& Kanungo, 1988) consists of feelings of competence, self-determination, autonomy in work processes, along with a feeling of being able to have an impact on organizational outcomes. Structural empowerment refers to elements such as opportunities to grow and develop, resources that include supplies and equipment, flexibility, and access to data. It also includes support from managers and peers as well as alliances both inside and outside of the organization (Kanter, 1979). A more contemporary and concise view is that empowerment involves shifting responsibility and authority to make decisions to employees (Ford et al., 1995) with the intention of enhancing organizational performance and effectiveness. Following a downsizing, empowerment has been considered an active coping resource that provides survivors a sense of hope and control (Mishra \& Spreitzer, 1998). Further, empowered employees experience higher levels of job satisfaction and lower levels of job related strain (Spreitzer, Kizilos, \& Nason, 1997).

In the context of Karasek's Job Demands-Control model, empowerment is expected to buffer the effects of role-overload on burnout and to enhance satisfaction. Moreover, Häusser et al. (2010) argued that moderators may be more effective buffers if they matched the level of work demands. For example, decision latitude that has an effect at the job level (as opposed to the task level) should reduce associated job strains more than decision latitude provided at the task level. Given the quantitative focus of role overload and the decision authority provided by empowerment that could enable work efficiencies, we predict:

Hypothesis 1a: The positive relationship between role overload and burnout is moderated by empowerment such that empowerment weakens the role overload-burnout relationship.

Hypothesis 1b: The negative relationship between role-overload and job satisfaction is moderated by empowerment such that empowerment weakens the role overload-job satisfaction relationship.

\section{Informational Justice as Low Control}

Informational justice refers to the thoroughness, level of detail, and timeliness supervisors use when explaining policies and procedures to subordinates (Bies \& Moag, 1986; Shapiro, Buttner, \& Barry, 1994). Perceptions of high informational justice occur when these 
explanations are thorough, detailed, candid, reasonable, and timely (Greenberg, 1990; 1993). However, the more supervisors explain how work should be done, the less freedom subordinates have in how they do their job. Taking this tradeoff into consideration, we perceive high informational justice as a low control environment.

Environments high in informational justice may be indicative of workplaces that are rigid and mechanistic (Andrews, Kacmar, \& Harris, 2009). Work behaviors in mechanistic organizations are guided by the decisions and instructions provided by supervisors and the methods for performing each functional role are clearly defined (Burns \& Stalker, 1961). Moreover, some have theorized that limiting control of workers through procedures and rules can help to reduce internal uncertainties (Goldman \& Van Houten, 1977). For example, in some industries (e.g., pharmaceutical, healthcare, airlines, etc.) timeliness of conveying detailed information to employees regarding policies and procedures is critical in order to prevent errors.

Thus, high informational justice may be construed as controlling (rather than as offering control) as it is suggestive of a rule bound environment. This type of environment may limit flexibility of employees and their ability to complete additional work upon demand. Furthermore, a rigid environment may inhibit individuals' ability to actively and constructively cope with role stress brought on by extra work. However, if employees are not experiencing added responsibilities (i.e., low overload), supervisors' explanations and clarification of rules may indeed enhance satisfaction and reduce burnout. Considering Karasek's Job DemandControl framework, informational justice may limit workers' control by limiting their ability to make decisions regarding their jobs. Hauser et al.'s (2010) matching principle applies here as well. Informational justice may severely limit decision latitude as policies and procedures regarding one's work are thoroughly explained and the importance of following these policies is reiterated.

Hypothesis 2a: The positive relationship between role-overload and burnout is moderated by informational justice such that informational justice strengthens the role overloadburnout relationship.

Hypothesis $2 \mathrm{~b}$ : The negative relationship between role-overload and job satisfaction is moderated by informational justice such that informational justice strengthens the role overload- job satisfaction relationship.

\section{Method}

\section{Sample}

The data were collected on site from 159 employees of a pharmaceutical manufacturing firm located in the eastern United States. Surveys were administered at two time periods (roughly 6 months apart) to employees from three divisions of the firm: Research and Development, Quality Control, and BioAnalytical. Employees of these divisions were asked by management to attend one of two sessions to complete the survey. In these sessions, the researchers distributed the surveys to the respondents and encouraged them to answer honestly. The participants were assured anonymity and confidentiality. Only participants who responded at both points in time were included in our analyses as variables collected in the first round were used as the independent variables and variables collected in the second round were used as the dependent variables. The sample consisted of $83(52 \%)$ males and $76(48 \%)$ females with a mean age of 33.61 years. To help protect the anonymity of the respondents and to encourage a strong 
response, tenure was measured categorically $(0=$ less than 1 year, $1=1-5$ years, and $2=$ more than 5 years). Responses to the tenure question indicated that $50 \%$ of the sample had been with the organization more than 5 years while $10 \%$ of the sample had been with the organization less than 1 year leaving $40 \%$ of the sample in the $1-5$ year range.

\section{Measures at Time 1}

Empowerment. The empowerment scale consisted of 10 items from the empowerment scale reported in Niehoff, Moorman, Blakely, and Fuller (2001). Responses were made on a 7-point scale ( $1=$ never to $7=$ always). The items included a variety of behaviors that a manager would exhibit in an empowering situation. Sample items include "wants me to get involved when I see a need and not wait to be told or given permission" and "helps remove roadblocks." Cronbach's alpha for this scale was .94 .

Role overload. Role overload was measured with three items from the scale developed by Beehr, Walsh, and Taber (1976). Responses were made on a 7-point scale (1=strongly disagree to $7=$ strongly agree). For example, one of the items was "It often seems like I have too much work for one person to do." Cronbach's alpha for this measure was 75.

Justice. Justice was measured with the 20 item scale developed by Colquitt (2001). The scale measures four justice dimensions; procedural justice measured by seven items $(\alpha=92)$, distributive justice measured by four items $(\alpha=95)$, interpersonal justice measured by four items $(\alpha=94)$, and informational justice measured by five items $(\alpha=88)$. Informational justice is the form of justice of interest in the current study. The other three forms of justice were included as control variables to ensure that the full complement of the construct of justice was covered. Results with and without controlling for the three forms of justice were similar. We present the results with control variables to offer a more conservative test.

\section{Measures at Time 2}

Job satisfaction. Job satisfaction was measured with the Minnesota Satisfaction Questionnaire (Weiss, Dawis, England, \& Lofquist, 1967). A total of 20 items were included with a sample being "To what extent are you satisfied with: the feeling of accomplishment I get from the job." Respondents used a 5-point scale ( $1=$ very dissatisfied and $5=$ very satisfied) Cronbach's alpha for this scale was 90 .

Burnout. Burnout (emotional exhaustion) was measured with the nine burnout items from the Maslach Burnout Inventory (Maslach \& Jackson, 1981, 1986). A sample item is "I feel emotionally drained from my work." Responses were made on a 1-strongly disagree 7 scale with strongly disagree and strongly agree as anchors. Cronbach's alpha for this scale was 90.

\section{Analysis}

To test our hypotheses, we used SPSS 19 to conduct two separate four-step multiple moderated regression analyses, one for each dependent variable collected at time 2: job satisfaction and burnout. In the first step, we entered the control variables which consisted of the 
three forms of justice not serving as a moderator: procedural, distributive, and interpersonal. In the second step, we entered the main effect, role overload. In the third step we entered both moderators, empowerment and informational justice. In the fourth step, we entered both interaction terms formed by multiplying role overload by empowerment and informational justice. The independent and moderator variables were centered prior to their inclusion in the analyses or their use in creating the interaction terms (Cohen, Cohen, West, \& Aiken, 2003).

\section{Results}

Table 1 displays the descriptive statistics for and the correlations among the variables of interest in our study. Prior to testing our hypotheses, we conducted a confirmatory factor analysis (CFA) using LISREL 8.8 on the scales used in our study to ensure that they were independent and that the items produced the expected factor structures. Our measurement model consisted of eight factors, one for each of our scales (i.e., role overload, empowerment, burnout, job satisfaction, and the four forms of justice). Fit indices showed that the 8-factor model fit the data well $(\mathrm{CFI}=.94 ; \mathrm{NNFI}=94 ; \mathrm{RMSEA}=.062)$ and all of the standardized path loadings were significant $(p<.01)$.

Although the results for the measurement model provide support for the independence of our variables, several correlations in Table 1 were greater than .60 suggesting that some of our scales may not be distinct. Thus, we ran several alternative models that combined scales with high correlations to confirm that an 8-factor model was the best representation of our data. The first alternative model created one factor for the justice scales resulting in a 5-factor model. The model fit for this model $(\mathrm{CFI}=.90 ; \mathrm{NNFI}=90 ; \mathrm{RMSEA}=.095)$ was not as strong as for the full measurement model and the chi-square difference test $\left(X_{\text {diff }}^{2}(18)=1062, p<.001\right)$ was significant indicating that collapsing the justice scales into one factor did not produce a better fitting model. The second alterative model collapsed the two dependent variables into one model producing a 6-factor model. Once again, the model fit for this model (CFI = .93; NNFI = 92; RMSEA = .081) was not as strong as for the full measurement model and the chi-square difference test $\left(X_{\text {diff }}^{2}(7)=421, p<.001\right)$ was significant indicating that collapsing the dependent variables into one factor did not produce a better fitting model. The final alternative model collapsed the two moderators into one factor producing a 6-factor model. Like the other two alternative models, the model fit for this model $(\mathrm{CFI}=.93$; NNFI $=92$; RMSEA $=.075)$ was not as strong as for the full measurement model and the chi-square difference test $\left(X_{\text {diff }}^{2}(7)=186, p\right.$ $<.001$ ) was significant indicating that collapsing the two moderators into one factor did not produce a better fitting model. Taken together, these results demonstrate support for the independence of our scales. 
Table 1

Means, Standard Deviations, and Correlations

\begin{tabular}{|c|c|c|c|c|c|c|c|c|c|}
\hline Variable & Mean & SD & 1 & 2 & 3 & 4 & 5 & 6 & 7 \\
\hline 1. Role Overload (Time 1) & 3.29 & 0.57 & & & & & & & \\
\hline 2. Empowerment (Time 1) & 4.06 & 1.51 & 0.12 & & & & & & \\
\hline 3. Informational Justice (Time 1) & 4.02 & 1.36 & $0.18 *$ & $0.57 * * *$ & & & & & \\
\hline 4. Job Satisfaction (Time 2) & 3.33 & 0.63 & -0.00 & $0.16^{*}$ & 0.09 & & & & \\
\hline 5. Burnout (Time 2) & 3.75 & 1.26 & 0.06 & -0.08 & -0.07 & $-0.61 * * *$ & & & \\
\hline 6. Procedural Justice (Time 1) & 3.25 & 1.40 & $0.17 *$ & $0.55^{* * *}$ & $0.67 * * *$ & -0.03 & 0.10 & & \\
\hline 7. Distributive Justice (Time 1) & 3.71 & 1.70 & 0.14 & $0.39 * * *$ & $0.51 * * *$ & -0.01 & 0.05 & $0.67 * * *$ & \\
\hline 8. Interpersonal Justice (Time 1) & 4.07 & 1.63 & $0.23 * *$ & $0.52 * * *$ & $0.77 * * *$ & 0.01 & 0.02 & $0.64 * * *$ & $0.58 * * *$ \\
\hline
\end{tabular}

$\mathrm{N}=159$.

$* p<.05 . * * p<.01 . * * * p<.001$. 
Table 2

Hierarchical Moderated Multiple Regression Results

DV: Job Satisfaction Time $2 \quad$ DV: Burnout Time 2

\begin{tabular}{|c|c|c|c|c|c|c|}
\hline Variables & Beta & $F$-step (df) & $\Delta R^{2}$ & Beta & $F$-step (df) & $\Delta R^{2}$ \\
\hline Step 1: Controls & & $<1(3,155)$ & .003 & & $<1(3,155)$ & .014 \\
\hline Procedural Justice & -.068 & & & .156 & & \\
\hline Distributive Justice & .004 & & & -.014 & & \\
\hline Interpersonal Justice & .053 & & & -.072 & & \\
\hline Step 2: Main Effect & & $<1(4,154)$ & .003 & & $<1(4,154)$ & .000 \\
\hline Procedural Justice & -.061 & & & .154 & & \\
\hline Distributive Justice & -.004 & & & -.010 & & \\
\hline Interpersonal Justice & .033 & & & -.063 & & \\
\hline Role Overload & -.053 & & & .022 & & \\
\hline Step 3: Moderators & & $1.59(6,152)$ & $.054^{*}$ & & $1.81(6,152)$ & $.053^{*}$ \\
\hline Procedural Justice & -.220 & & & .315 & & \\
\hline Distributive Justice & .022 & & & -.039 & & \\
\hline Interpersonal Justice & -.138 & & & .138 & & \\
\hline Role Overload & -.011 & & & -.023 & & \\
\hline Empowerment & $.223^{*}$ & & & -.154 & & \\
\hline Informational Justice & .203 & & & $-.292^{*}$ & & \\
\hline Step 4: Interactions & & $2.99(8,150)^{* *}$ & $.079^{* *}$ & & $2.37(8,150)^{*}$ & $.045^{*}$ \\
\hline Procedural Justice & -.212 & & & .311 & & \\
\hline Distributive Justice & -.014 & & & -.038 & & \\
\hline Interpersonal Justice & -.159 & & & .166 & & \\
\hline Role Overload & .019 & & & -.032 & & \\
\hline Empowerment & $.196^{*}$ & & & -.114 & & \\
\hline Informational Justice & $.279^{*}$ & & & $-.345^{* *}$ & & \\
\hline Role Overload X Empowerment & $-.346^{* * *}$ & & & $.233^{* *}$ & & \\
\hline Role Overload X Informational Justice & $.195^{*}$ & & & $-.231^{* *}$ & & \\
\hline
\end{tabular}

$\mathrm{N}=159 * \mathrm{p}<.05 . * * \mathrm{p}<.01 . * * * \mathrm{p}<.001 . \mathrm{DV}=$ Dependent Variable 
Results for the tests of our hypotheses can be found in Table 2. Hypothesis 1 predicted that empowerment would moderate the relationships between role overload and burnout (H1a) and between role overload and job satisfaction (H1b). As can be seen in Step 4 of Table 2, after controlling for the three forms of justice not serving as a moderator, the role overload empowerment interactions were significant for both burnout and job satisfaction measured at time 2. To determine whether these significant interactions provided support for Hypothesis 1, we need to see if the form of these relationships aligns with our predictions. To do this, we graphed the significant interactions using a procedure similar to that used by Stone and Hollenbeck (1989). As conventionally done, we plotted two slopes: one at one standard deviation below the mean and one at one standard deviation above the mean (Aiken \& West, 1991). We graphed our results so that we can see the combined effects of the independent and moderating variables on the dependent variable. Specifically, our graphs illustrate the impact of the independent variable on the dependent variable at various (i.e., high and low) values of the moderator. The plots are shown in Figure 2.

Consistent with Hypothesis 1 and as demonstrated via simple slope tests for the significant interactions (Cohen et al., 2003), among employees reporting high levels of empowerment, the negative relationship between overload and burnout at Time 2 was significantly stronger $(t=-2.05, p=.02$, one-tailed) than for those employees reporting low levels of empowerment $(t=1.57$, ns). Similarly, among employees reporting high levels of empowerment, the positive relationship between overload and job satisfaction at Time 2 was significantly stronger $(t=1.70, p=.05$, one-tailed) than for those employees reporting low levels of empowerment $(t=1.40, \mathrm{~ns})$. Thus, the forms of the interactions confirm the relationships predicted in Hypothesis 1.

Hypothesis 2 predicted that informational justice would moderate the relationships between role overload and burnout (H2a) and between role overload and job satisfaction (H2b). As can be seen in Step 4 of Table 2, the role overload - informational justice interactions were significant for both burnout and job satisfaction measured at time 2 after controlling for the three forms of justice not included as a moderator. To determine whether these significant interactions provided support for Hypothesis 2, we once again graphed them. The plots are shown in Figure 3. Consistent with Hypothesis 2 and as demonstrated via simple slope tests for the significant interactions (Cohen et al., 2003), among employees reporting high levels of informational justice, the relationship between role overload and burnout at Time 2 was positive $(t=1.75, p=$ .04 , one-tailed) and negative for those reporting low levels of informational justice $(t=-1.92, p=$ .03 , one-tailed). Conversely, among employees reporting high levels of informational justice, the relationship between overload and job satisfaction at Time 2 was negative $(t=-2.61, p=.005$, one-tailed) and positive for those employees reporting low levels of informational justice ( $t=$ $2.91, p=.002$, one-tailed). Thus, the forms of the interactions confirm the relationships predicted in Hypothesis 2. 

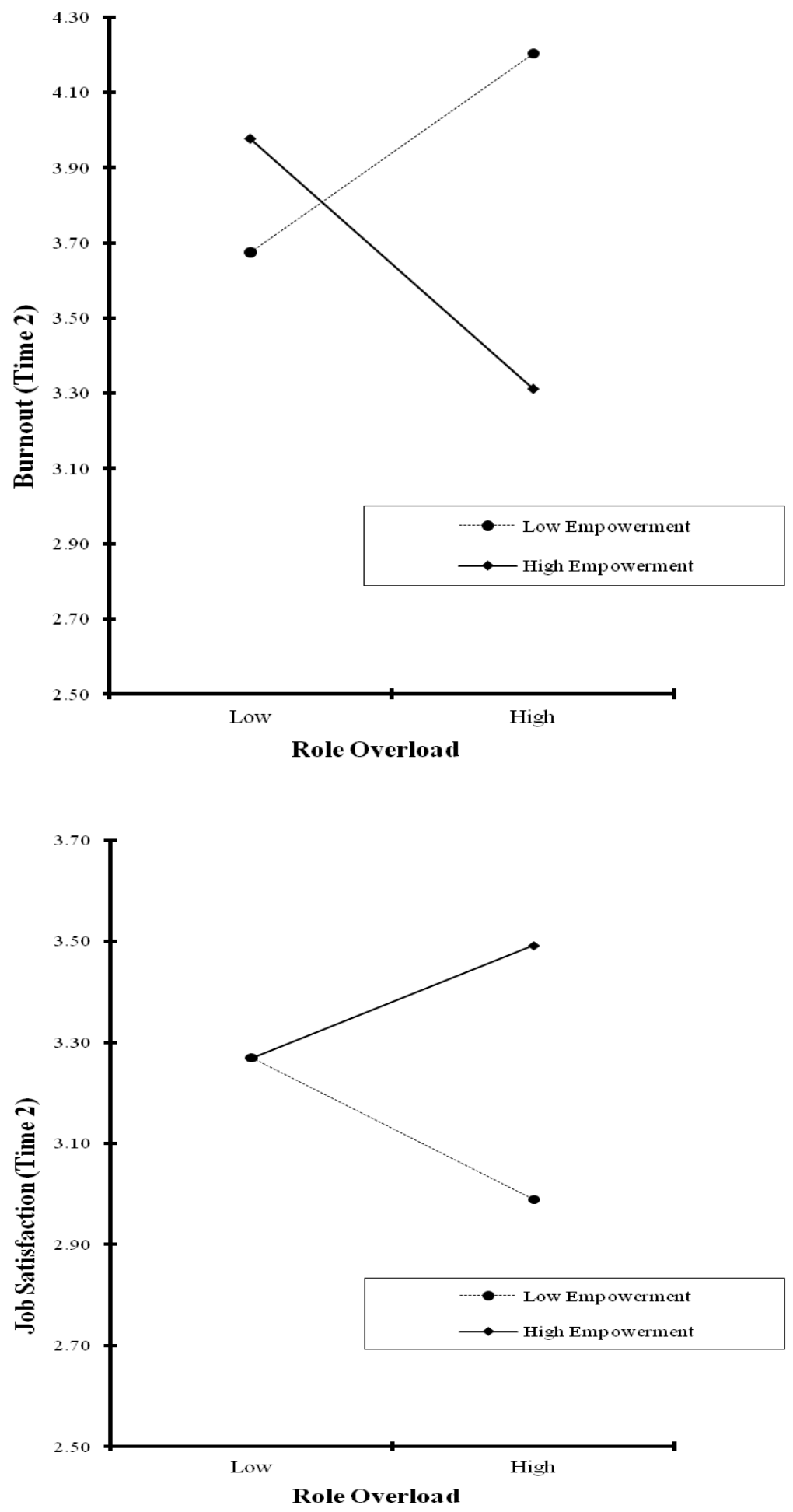

Figure 2. Interaction results for empowerment as moderator. 

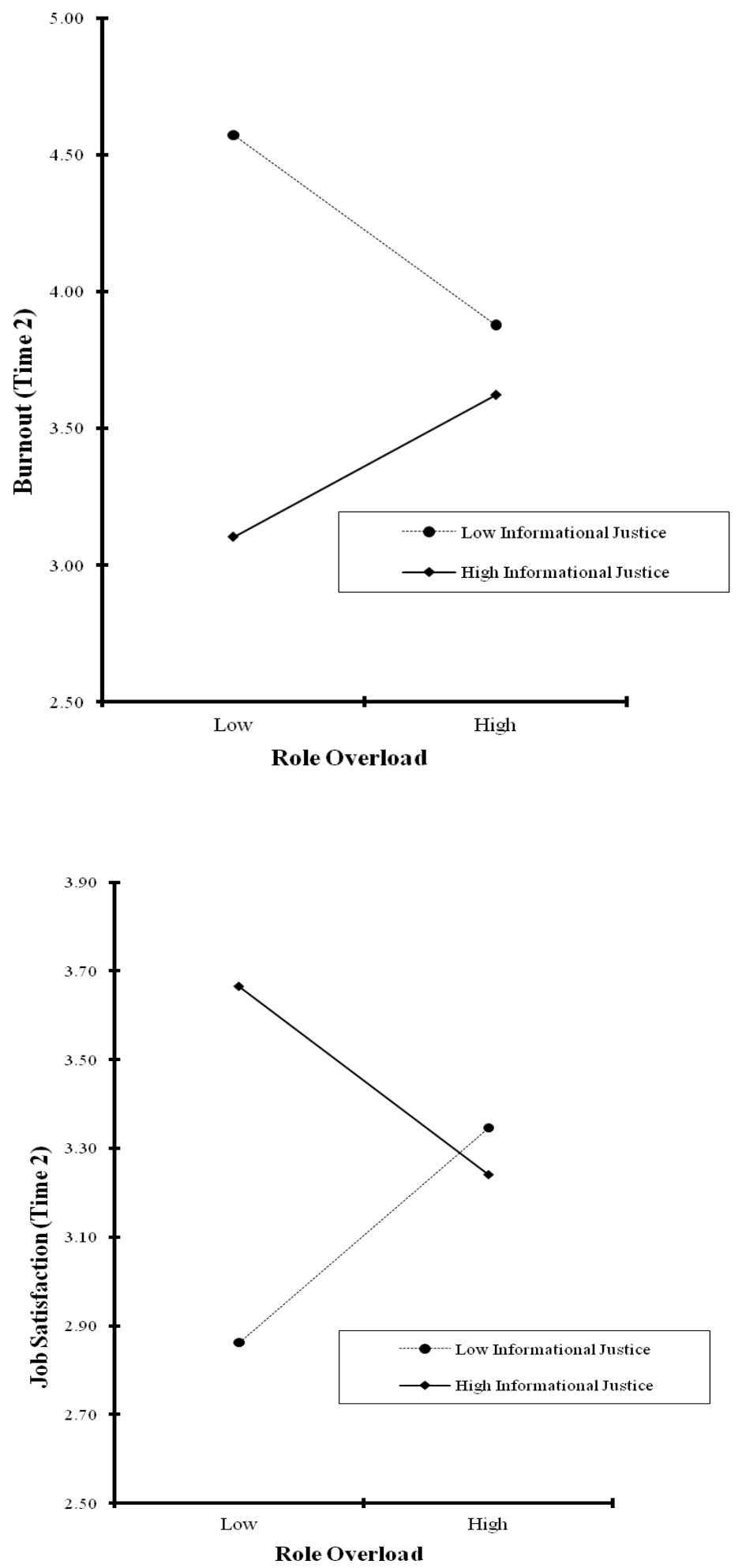

Figure 3. Interaction results for informational justice as moderator. 


\section{Discussion}

The findings of the present study provide additional support for Karasek's (1979) Job Demand-Control model using two operationalizations of control: empowerment and informational justice. Specifically, we conceived of empowerment as high decision latitude, thus, providing workers high control in making decisions about how they complete their work. Informational justice was considered low control (i.e., low decision latitude) as the communications provided by supervisors that clarified reasons for policies and procedures limited workers ability to make decisions. These variables served to test the interactive effects suggested in the buffer hypothesis (van der Doef \& Maes, 1999).

Hypothesis 1a was supported and stated that empowerment, a form of high control, buffered the positive effects of role overload on burnout. Not only were the positive effects of role overload on burnout weakened, but as seen in Figure 1, the relationship was reversed under conditions of high empowerment. Under conditions of high empowerment, high role overload resulted in the lowest level of burnout. This finding is consistent with Karasek's (1979) assertion that active jobs (i.e., high strain and high control) will result in the most favorable outcomes. Figure 1 also demonstrates that high strain jobs (i.e., high demand and low control) result in the highest level of burnout.

Hypothesis $1 \mathrm{~b}$ was also supported which stated that empowerment would weaken the negative effects of role overload on job satisfaction. Similar to the finding for burnout, the most favorable outcome resulted from high strain and high control and was again consistent with expectations for active jobs. Specifically, the highest level of satisfaction resulted when employees experienced high role overload accompanied by high empowerment. The lowest level of satisfaction occurred under high role overload and low empowerment. The findings for Hypotheses 1a and 1b support Karasek's (1979) theory that active and high strain jobs result in the most favorable and the most unfavorable outcomes, respectively. These findings also support views of other researchers. First, moderating variables can play an important part in tempering the negative effects of role strain (Ganster, 1989). Second, the matching hypothesis (Cohen \& Wills, 1985, Häusser et al., 2010) may indeed allow researchers to generate consistent findings with respect to strength of the effects of moderating variables.

Hypotheses $2 \mathrm{a}$ and $2 \mathrm{~b}$ were supported as well and indicated that informational justice, conceived of as low control, strengthens the positive relationship between role overload and burnout and the negative relationship between role overload and job satisfaction after controlling for procedural, distributive, and interpersonal justice. As indicated in Figure 2, role overload led to increased burnout under conditions of high informational justice and decreased burnout under conditions of low informational justice. For the outcome of job satisfaction there were similar results. Job satisfaction increased as role overload increased under conditions of low informational justice and decreased under conditions of high informational justice. These findings suggest that when employees experience low role overload, informational justice can help to maintain job satisfaction keeping burnout low. However, as role overload increases, such as after a layoff, informational justice may be less important in controlling burnout and maintaining satisfaction. Once other forms of justice are in place, explanations provided by supervisors may simply get in the way of productivity as they do not provided an active mechanism of support. Supervisor communications do not help get the work completed but rather interfere with workers' ability to effectively deal with the increased workload. 
As with any study, there are a number of limitations. First, the data were self report introducing the possibility of common method variance. However, because some of the variables were collected at a second time period, this should be limited. Second, the data were collected from employees of a single organization thereby limiting the generalizability of these findings. This study should be replicated across other organizations and industries. Finally, our study included only perceptual outcomes. Behavioral outcomes including objective performance measures and/or supervisor rated OCB are other important outcomes to assess.

Despite these limitations, our findings make a number of contributions to both the stress and justice literature. First, with respect to the stress literature, our findings not only confirm traditional findings of Karasek's active and high strain jobs, but add clarity to the mixed findings regarding the importance of control as a buffering variable in stressor-strain relationships. This study also provides a test of the matching principle (Cohen \& Wills, 1985; Häusser et al., 2010) which suggests matching the level of control with the level of strain. Specifically, we operationalized control as empowerment which allows for worker control over how to address the increased workload. Our study also makes a unique contribution to the justice literature by conceiving of informational justice as low control, thereby providing a limit on workers' decision latitude to effectively deal with role stress. After controlling for three forms of justice, informational justice, while appearing useful on the surface, actually may hinder ability to complete work. Thus, informational justice appears to be most useful when workloads are manageable (i.e., low role overload) and potentially harmful when workloads are heavy.

Finally, these results provide guidance for human resource managers in setting policies. Specifically, following a reduction in force, if the workload is substantially increased, empowerment may be an effective strategy for reducing burnout and maintaining job satisfaction among survivors. Supervisor explanations may be limited in their usefulness in this situation as time spent explaining the reasons for policies may actually interfere with the ability of workers to meet the demands of the increased workload. As long as procedural and distributive justice are in place, additional supervisor communications may be unnecessary. If employees are not experiencing role strain, then it appears supervisors should spend time providing additional explanations to employees regarding the rationale for policies.

\section{References}

Aiken, L. S., \& West, S. G. (1991). Multiple regression: Testing and interpreting interactions. Newbury Park: Sage.

Andrews, M.C., Kacmar, K.M., Harris, K.J. (2009). Got political skill? The impact of justice on the importance of political skill for job performance. Journal of Applied Psychology, 94(6), 1427-1437.

Beehr, T. A., Walsh, J. T., \& Taber, T. D. (1976). Relationship of stress to individually and organizationally valued states: Higher order needs as a moderator. Journal of Applied Psychology, 61, 41-47.

Bies, R.J., \& Moag, J.F. (1986). Interactional justice: Communication criteria of fairness. In R.J. Lewicki, B.H. Sheppard, \& M.H. Bazerman (Eds.), Research on negotiations in organizations, 1, 43-55. Greenwich, CT: JAI Press.

Burns, T., \& Stalker, G.M. (1961). The Management of Innovation, 119-125, London: Tavistock Publications. 
Caplan, R. D., Cobb, S., French, J. R., Harrison, R. V. \& Pinneau, S. R. (1975). Job Demands and Workers Health, HEW (NIOSH), U.S. Government Printing Office, Washington, D.C.

Chou, R.J., \& Robert, S.A. (2008). Workplace support, role overload, and job satisfaction of direct care workers in assisted living. Journal of Health and Social Behavior, 49, 208222.

Cohen, J., Cohen, P, West, S, \& Aiken, L. (2003). Applied multiple regression/correlation analysis for the behavioral sciences (3rd Ed.). Mahway, NJ: Erlbaum.

Cohen, S., \& Wills, T. A. (1985). Stress, social support, and the buffering hypothesis. Psychological Bulletin, 98(2), 310-357.

Colquitt, J. A. (2001). On the dimensionality of organizational justice: A construct validation of a measure. Journal of Applied Psychology, 86, 386-400.

Conger, J. A., \& Kanungo, R. N. (1988). The empowerment process: integrating theory and practice. Academy of Management Review, 13(3), 471-482.

Cordes, C. L. \& Dougherty, T. W. (1993). A review and an integration of research on job burnout. Academy of Management Review, 18, 621-656.

Dwyer, D. J., \& Ganster, D. C. (1991). The effects of job demands and control on employee attendance and satisfaction. Journal of Organizational Behavior, 12, 595-608.

Ford, R., Fottler, M., Russ, D.E., \& Millam, E.R. (1995). Empowerment: A matter of degree. Academy of Management Executive, 9(3), 21-29.

Ganster, D. C. (1989). Worker control and well-being: A review of research in the workplace. In S. L. Sauter, J. J. Hurrell, \& C. L. Cooper (Eds.), Job Control and Worker Health (pp. 324). Chichester: Wiley.

Goldman, P., \& Van Houten, D. R. (1977). Managerial Strategies and the Worker: a Marxist Analysis of Bureaucracy. Sociological Quarterly, 18(1), 108-125.

Greenberg, J. (1990). Employee theft as a reaction to underpayment inequity: The hidden cost of pay cuts. Journal of Applied Psychology, 75, 561-568.

Greenberg, J. (1993). The social side of fairness: Interpersonal and informational classes of organizational justice. In R. Cropanzano (Ed.), Justice in the Workplace: Approaching Fairness in Human Resource Management (pp. 79-103). Hillsdale, NJ: Erlbaum.

Häusser, J., Mojzisch, A., Niesel, M., \& Schulz-Hardt, S. (2010). Ten years on: A review of recent research on the job demand-control (-support) model and psychological wellbeing. Work \& Stress, 24, 1-35.

Jones, E., Chonko, L., Rangarajan, D. \& James, R. (2007). The role of overload on job attitudes, turnover intentions, and salesperson performance. Journal of Business Research, 60(7), 663-671.

Kanter, R.M. (1979). Power failure in management circuits. Harvard Business Review, 57, 6575.

Karasek, R.A. (1979). Job demands, job decision latitude, and mental strain: Implications for job redesign. Administrative Science Quarterly, 24(2), 285-308.

Kissner, R. (1999). Job demands and occupational stressors in social work: Main effects and interactions. Dissertation Abstracts International Section A, 60.

Malik, O., Waheed, A., \& Malik, K. (2010). The Mediating Effects of Job Satisfaction on Role Stressors and Affective Commitment. International Journal of Business \& Management, 5(11), 223-235. 
Maslach, C. \& Jackson, S. E. (1981). The measurement of experienced burnout. Journal of Occupational Behavior, 2, 99-115.

Maslach, C., \& Jackson, S. E. (1986). Maslach Burnout Inventory Manual (2nd ed.). Palo Alto, CA: Consulting Psychologists Press.

Mishra, A.K., \& Spreitzer, G.M. (1998). Explaining how survivors respond to downsizing: The roles of trust, empowerment, justice, and work redesign. The Academy Of Management Review, 23(3), 567-588.

Niehoff, B. P., Moorman, R. H., Blakely, G. L., \& Fuller, J. (2001). The influence of empowerment and job enrichment on employee loyalty in a downsizing environment. Group and Organization Management, 26, 93-113.

Parker, S. K., \& Sprigg, C. A. (1999). Minimizing strain and maximizing learning: The role of job demands, job control, and proactive personality. Journal of Applied Psychology, 84(6), 925-939.

Rizzo, J. R., House, R. J., \& Lirtzman, S. I. (1970). Role conflict and ambiguity in complex organizations. Administrative Science Quarterly, 15(2), 150-163.

Shapiro, D. L., Buttner, E., \& Barry, B. (1994). Explanations: What factors enhance their perceived adequacy? Organizational Behavior and Human Decision Processes, 58(3), 346-368.

Shultz, K., Wang, M., \& Olson, D. (2010). Role overload and underload in relation to occupational stress and health. Stress \& Health: Journal of the International Society for the Investigation of Stress, 26(2), 99-111.

Spreitzer, G. M., Kizilos, M. A., \& Nason, S. W. (1997). A dimensional analysis of the relationship between psychological empowerment and effectiveness, satisfaction, and strain. Journal of Management, 23(5), 679.

Stone, E. F., \& Hollenbeck, J. R. (1989). Clarifying some controversial issues surrounding statistical procedures for detecting moderating variables: Empirical evidence and related matters. Journal of Applied Psychology, 74, 3-10.

van der Doef, M., \& Maes, S. (1999). The Job Demand-Control (-Support) model and psychological well-being: A review of 20 years of empirical research. Work \& Stress, 13, $87-114$.

Weiss, D.J., Dawis, R.V., England, G.W., \& Lofquist, L.H. (1967). Manual for the Minnesota Satisfaction Questionnaire. Minneapolis: University of Minnesota, Industrial Relations Center, Work Adjustment Project.

Wincent, J., \& Örtqvist, D. (2011). Examining positive performance implications of role stressors by the indirect influence of positive affect: A study of new business managers. Journal of Applied Social Psychology, 41(3), 699-727.

Yip, B., Rowlinson, S., \& Oi Ling, S. (2008). Coping strategies as moderators in the relationship between role overload and burnout. Construction Management \& Economics, 26(8), 869880 . 